\title{
EXPERIMENTAL STUDY ON THE EFFICIENCY OF DIFFERENT SUBSTANCES IN RETARDING THE ABSORPTION OF PENICILLIN INTRODUCED INTO THE SUBCONJUNCTIVAL SPACES*
}

BY

\author{
GIUSEPPE LEPRI \\ From the Eye Clinic, University of Pisa, Italy. \\ Director, Prof. F. Caramazza
}

THERE is no doubt that therapeutic levels of penicillin can be obtained in the aqueous and the tissues of the anterior segment of the globe, by injecting correct doses of the antibiotic subconjunctivally. Such levels are slightly higher than those reached with equal doses by systemic administration (Sorsby and Ungar, 1946-48; Andrews, 1947).

The degree of impurity shown by the first preparations of the antibiotic did not permit the quantity of penicillin introduced at each in jection to exceed 10,000 to 20,000 units dissolved in $0.5 \mathrm{ml}$. distilled water. The high degree of purity obtainable at the present time, and the perfect solubility of the substance, now permit the introduction of 500,000 to $1,000,000$ units dissolved in $0.5 \mathrm{ml}$. distilled water, preceded by a simple cocaine anaesthesia. These large doses admit the advantage of reaching the highest concentration in the aqueous and ocular tissues, but do not prevent the rapid elimination of the substance from the subconjunctival area backward through the lymphatic epibulbar spaces. This constitutes a great obstacle to the common use of the drug in subconjunctival injections, on account of the frequency with which the injections must be administered.

Some substances have recently been tested to discover an agent which, when injected locally with penicillin, will to some degree retard its absorption.

In order to determine the degree to which such substances can retard the absorption of penicillin, we have carried out research, under various conditions, into the rhythm with which the drug passes into the aqueous, together with the blood level. In a series of experiments on rabbits, we tested the efficiency of several associations as follows :

(1) Association of adrenalin 1:1,000 with penicillin.

(2) Association of pectine.

(3) Association of procaine.

(4) Association of procaine-pectine.

* Received for publication November 11, 1949. 
We did not consider the use of penicillin in oil or oil-wax, according to Romansky's formula, because of the particular place where the injection was made. Some tests already made with these substances provoked the formation of hard subconjunctival swellings, which were absorbed with great difficulty, and caused considerable reactive symptoms.

\section{Experimental Technique}

The subconjunctival injections were all performed by the same technique. The blood and the aqueous were removed by the same methods and kept in the refrigerator until the moment of estimation. For estimating the penicillin levels we employed the standard capillary tube method (Fleming, 1944).

(1) As a preliminary test we first determined the values obtained in the blood and aqueous after a subconjunctival injection of 100,000 units of pure crystalline sodium " $G$ " penicillin, dissolved in $0.5 \mathrm{ml}$. distilled water. From Table I it appears that the highest level is reached at the first hour, afterwards the level decreases until the sixth hour. The values obtainable in the blood are clearly lower, and decrease with greater rapidity, reaching zero after the end of the fourth hour.

TABLE I.

Effects of Subconjunctival Injection of 100,000 U. Crystalline Penicillin " G" in $0.5 \mathrm{ml}$. $\mathrm{H}_{2} \mathrm{O}$.

\begin{tabular}{|c|c|c|c|c|c|c|c|c|c|}
\hline \multirow{2}{*}{$\begin{array}{l}\text { Penicillin } \\
\text { Levels }\end{array}$} & \multirow{2}{*}{$\begin{array}{c}\text { Test } \\
\text { Animals }\end{array}$} & \multicolumn{8}{|c|}{ Number of Hours after Injection } \\
\hline & & 1 & 2 & 4 & 6 & 10 & 14 & 20 & 24 \\
\hline \multirow{3}{*}{$\begin{array}{l}\text { Aqueous } \\
\text { (units per } \\
\text { ml.) }\end{array}$} & 1 & $>30$ & 10 & 2 & $0 \cdot 3$ & 0 & - & - & - \\
\hline & 2 & $>20$ & 10 & $0 \cdot \overline{5}$ & 0 & - & - & $\ldots$ & - \\
\hline & 3 & 16 & 8 & 1 & $0 \cdot 2$ & 0 & - & $\ldots$ & - \\
\hline \multirow{3}{*}{$\begin{array}{c}\text { Blood } \\
\text { (units per } \\
\text { ml.) }\end{array}$} & 1 & 12 & 4 & 0 & 0 & - & $\ldots$ & 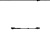 & 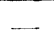 \\
\hline & 2 & 6 & $1 \cdot 5$ & 0 & 0 & - & - & - & - \\
\hline & 3 & 8 & 2 & 0.2 & 0 & - & - & - & $\cdots$ \\
\hline
\end{tabular}

(2) According to the repeated experiments of Sorsby and Ungar the subconjunctival introduction of adrenalin $(1$ in 1,000$)$ as solvent of the penicillin raises the levels and prolongs the permanence of the antibiotic both in the aqueous and in the blood. These results, already seen in low doses of the drug $(20,000$ to 50,000 units), are much better defined, as is shown by the above mentioned authors, through the subconjunctival introduction of $1,000,000$ units in the same solvent.

As in the test made without adrenalin, we introduced subconjunctivally 100,000 units of pure crystalline penicillin " $G$ " in $0.5 \mathrm{ml}$. adrenalin $(1$ in 1,000$)$. The results are shown in Table II.

From the above table it clearly appears that adrenalin exerts a marked effect in raising the level of penicillin in the aqueous and in causing a longer persistence of the antibiotic. On the blood levels the retarding effect is less pronounced, 
but nevertheless quite recognizable; at the sixth hour, and sometimes at the tenth hour, it is possible to find penicillin present in the blood, whereas without adrenalin the blood levels are close to zero after the fourth hour.

(3) Because of some results, rather clinical than experimental, pectine was suggested as a possible agent of retarding the absorption of penicillin, but tests of its efficiency in subconjunctival injections all failed.

TABLE II.

Subconjunctival Injection of $100,000 \mathrm{U}$. Penicillin in $0.5 \mathrm{ml}$. Adrenalin Solution (1 in 1000).

\begin{tabular}{|c|c|c|c|c|c|c|c|c|c|}
\hline \multirow{2}{*}{$\begin{array}{l}\text { Penicillin } \\
\text { Levels }\end{array}$} & \multirow{2}{*}{$\begin{array}{c}\text { Test } \\
\text { Animals }\end{array}$} & \multicolumn{8}{|c|}{ Number of Hours after Injection } \\
\hline & & 1 & 2 & 4 & 6 & 10 & 14 & 20 & 24 \\
\hline \multirow{3}{*}{$\begin{array}{c}\text { Aqueous } \\
\text { (units per } \\
\text { ml.) }\end{array}$} & 1 & $>20$ & $>20$ & $>16$ & 4 & 0.5 & $0 \cdot 1$ & 0 & - \\
\hline & 2 & $>30$ & 30 & 10 & 2 & 1 & 0 & - & - \\
\hline & 3 & 24 & $>16$ & 16 & 4 & 1 & $0 \cdot 2$ & 0 & - \\
\hline \multirow{3}{*}{$\begin{array}{l}\text { Blood } \\
\text { (units per } \\
\text { ml.) }\end{array}$} & 1 & 6 & 3 & $>1$ & 0.2 & 0 & 0 & - & - \\
\hline & 2 & 4 & 2 & 2 & 1 & 0.5 & $\mathbf{0}$ & 一 & - \\
\hline & 3 & 4 & 4 & 1 & 0.5 & 0 & 0 & - & - \\
\hline
\end{tabular}

We employed a colloidal solution of pectine 2 per cent. in water adjusted to a $p \mathrm{H}$ of $7 \cdot 2$; the penicillin was easily dissolved in the same proportion of 100,000 units in $0.5 \mathrm{ml}$. of the pectine solution.

The values obtained with the titration tests in vitro in the aqueous and blood are given in Table III.

\section{TABLE III.}

Subconjunctival Injection of 100,000 U. Penicillin dissolved in $0.5 \mathrm{ml}$. of a 2 per cent. Pectine Solution.

\begin{tabular}{c|c|c|c|c|c|c|c|c|c}
\hline \multirow{2}{*}{$\begin{array}{c}\text { Penicillin } \\
\text { Levels }\end{array}$} & $\begin{array}{c}\text { Test } \\
\text { Animals }\end{array}$ & \multicolumn{6}{|c}{ Number of Hours after Injection } \\
\cline { 2 - 10 } & 1 & 2 & 4 & 6 & 10 & 14 & 20 & 24 \\
\hline \multirow{2}{*}{$\begin{array}{c}\text { Aqueous } \\
\text { (units per } \\
\text { ml.) }\end{array}$} & 2 & 8 & 4 & - & 1 & $0 \cdot 2$ & 0 & - & - \\
\cline { 2 - 10 } & 3 & $>8$ & $>4$ & - & $0 \cdot 5$ & $0 \cdot 2$ & - & - & - \\
\hline $\begin{array}{c}\text { Blood } \\
\text { (units per } \\
\text { ml.) }\end{array}$ & 1 & 4 & 4 & 2 & $0 \cdot 2$ & 0 & - & - & - \\
\cline { 2 - 10 } & 2 & 4 & 1 & $0 \cdot 5$ & 0 & 0 & - & - & - \\
\hline
\end{tabular}


From the results obtained we concluded that pectine does show in reality a certain action in retarding the elimination of penicillin from the subconjunctival areas; but this action seems considerably limited compared with that shown by adrenalin. These results perhaps explain the mechanism through which pectine exerts its retarding action. This action, which is evidently developed in situ, must be bound up either with molecular complexes arising locally, or with a reduction in permeability of the local capillaries.

(4) The use of an insoluble salt of penicillin-procaine, either in water or oil suspension, has already been commonly employed in systemic administration. By this means the aim has been achieved of maintaining a therapeutic level of the antibiotic in the blood for a long time. In our experiments we used a preparation of penicillin-procaine in aqueous suspension, in which no foreign substances beyond a small amount of dispersing and stabilizing agents are present. The subconjunctival use of this drug did not provoke any noteworthy disturbance in the rabbit. The only points to be careful of are firstly to avoid the needle penetrating the blood vessels during the injection, secondly, to use a larger needle than that commonly employed in subconjunctival injections in order to prevent the occlusion of the lumen.

TABLE IV.

Subconjunctival Injection of 100,000 U. Procaine-penicillin " $G$ " suspended in $\mathrm{H}_{2} \mathrm{O}$.

\begin{tabular}{|c|c|c|c|c|c|c|c|c|c|}
\hline \multirow{2}{*}{$\begin{array}{l}\text { Penicillin } \\
\text { Levels }\end{array}$} & \multirow{2}{*}{$\begin{array}{c}\text { Test } \\
\text { Animals }\end{array}$} & \multicolumn{8}{|c|}{ Number of Hours after Injection } \\
\hline & & 1 & 2 & 4 & 6 & 10 & 14 & 20 & 24 \\
\hline \multirow{3}{*}{$\begin{array}{l}\text { Aqueous } \\
\text { (units per } \\
\text { ml.) }\end{array}$} & 1 & 20 & $>12$ & 8 & 4 & 1 & 0 & 0 & $\ldots$ \\
\hline & 2 & 16 & 10 & 4 & 2 & $0 \cdot 5$ & $0 \cdot 2$ & 0 & - \\
\hline & 3 & $>16$ & $>10$ & 6 & 1 & 1 & $0 \cdot 5$ & 0 & - \\
\hline \multirow{3}{*}{$\begin{array}{l}\text { Blood } \\
\text { (units per } \\
\text { ml.) }\end{array}$} & 1 & 6 & 6 & 4 & 4 & $>2$ & 2 & $0 \cdot 5$ & 0 \\
\hline & 2 & $>4$ & 4 & 4 & 2 & 1 & 1 & 0.5 & 0 \\
\hline & 3 & 6 & $>4$ & - & 2 & 1 & 0.5 & 0.2 & 0 \\
\hline
\end{tabular}

Lower concentrations are present at the first hour compared with those obtained by using penicillin dissolved in distilled water. On the contrary therapeutic levels of penicillin are found in both aqueous and blood as long as 14 hours after the injection. In some tests traces of penicillin were found in the blood up to 20 hours after the injection. Comparing this with the results obtained by the use of penicillin-adrenalin we notice that, while in the aqueous the values appear to be nearly similar, in the blood they seem higher and much more persistent.

(5) Finally we investigated the retarding action on the absorption of penicillin in the same experimental conditions, by a combination of procaine-pectine in colloidal solution. In this case also the combination with penicillin leads to the formation of some insoluble crystals of procaine penicillin. By carrying out the injection promptly we avoided the formation of these crystals, which only appear after 15 to 30 minutes.

From these results it is clear that the association of procaine-pectine affords no advantage in comparison with that obtained by other retarding processes; it is rather inferior to that of procaine alone. 


\section{Conclusions}

All the different substances having the faculty of retarding the absorption of penicillin by local action which we tested promote some degree of permanence in the subconjunctival spaces, when introduced subconjunctivally with penicillin.

TABLE V.

Subconjunctival Injection of 100,000 U. of Penicillin in Procaine-pectine Colloidal Solution.

\begin{tabular}{c|c|c|c|c|c|c|c|c|c}
\hline \multirow{3}{*}{$\begin{array}{c}\text { Penicillin } \\
\text { Levels }\end{array}$} & $\begin{array}{c}\text { Test } \\
\text { Animals }\end{array}$ & \multicolumn{7}{|c|}{ Number of Hours after Injection } \\
\cline { 2 - 9 } & 1 & 2 & 4 & 6 & 10 & 14 & 20 & 24 \\
\hline \multirow{3}{*}{ Blood } & 1 & 6 & 6 & 4 & 1 & 1 & 0 & - & - \\
\cline { 2 - 10 } & 2 & 10 & $>4$ & 4 & 2 & $0 \cdot 5$ & $0 \cdot 2$ & 0 & - \\
\hline \multirow{4}{*}{ Aqueous } & 10 & 6 & 2 & 2 & $0 \cdot 5$ & $0 \cdot 2$ & 0 & - \\
\hline & 2 & 4 & 4 & 2 & 1 & 1 & $0 \cdot 5$ & 0 & - \\
\hline & 4 & 2 & - & 1 & $0 \cdot 5$ & $0 \cdot 2$ & 0 & - \\
\hline
\end{tabular}

The intra-ocular penicillin levels, as can be seen from the values we found in the aqueous, are generally higher and much more persistent.

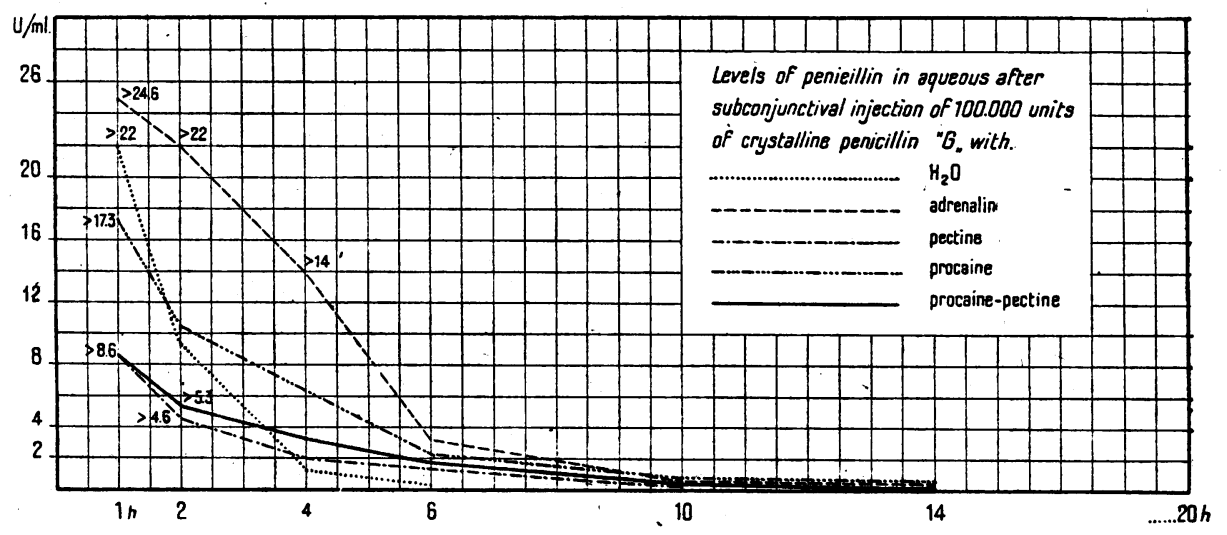

FIG. 1.-Graph showing mean penicillin levels in aqueous calculated from three experiments; details in Table I $\left(\mathrm{H}_{2} \mathrm{O}\right)$, Table II (adrenalin),

Table III (pectine), Table IV (procaine), Table V (procaine-pectine).

The most effective agents seem to be penicillin-procaine and penicillin-adrenalin. The first promotes high intra-ocular peni- 
cillin levels and also more persistent concentrations in the blood, which are close to those obtained by parenteral injections of the penicillin-procaine combination, and the second promotes heightened intra-ocular levels. (Figs 1 and 2)

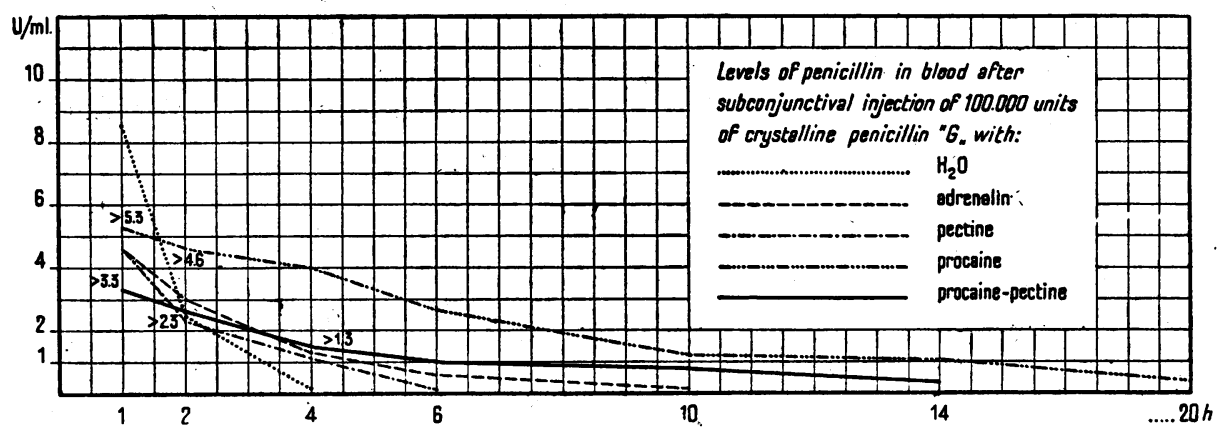

FIG. 2. Graph showing mean penicillin levels in blood calculated from three experiments; details in Table I $\left(\mathrm{H}_{2} \mathrm{O}\right)$. Table II (adrenalin), Table III (pectine), Table IV (procaine), Table V (procaine-pectine).

From the foregoing considerations it appears that, among the substances which develop a local retarding action, penicillinprocaine and penicillin-adrenalin are of the greatest importance, as being the most active in retarding the absorption of the antibiotic and in giving higher and more prolonged intraocular levels.

\section{Summary}

A study has been made of the effectiveness of different substances possessing a local retarding action, on the absorption of penicillin introduced subconjunctivally. According to these tests the penicillin-procaine and the penicillin-adrenalin combinations seem to be the most active.

The first succeeds particularly in prolonging the presence of the antibiotic both in the aqueous and in the blood; the second has only the important effect of promoting higher and more persistent intra-ocular concentrations of penicillin.

\section{REFERENCES}

ANDREWS, G. W. S. (1947). Lancet, 1, 594.

Fleming, A. (1944). Ibid., 2, 620.

SoRsBy, A., and READ, H. (1947). British Journal of Ophthalmology, 31, 528. and UNGAR, J. (1946). Brit. med. J., 2, 723

- (1948). British Journal of Ophthalmology, 32,-864. 